\section{Author(s):}

Submitted to:

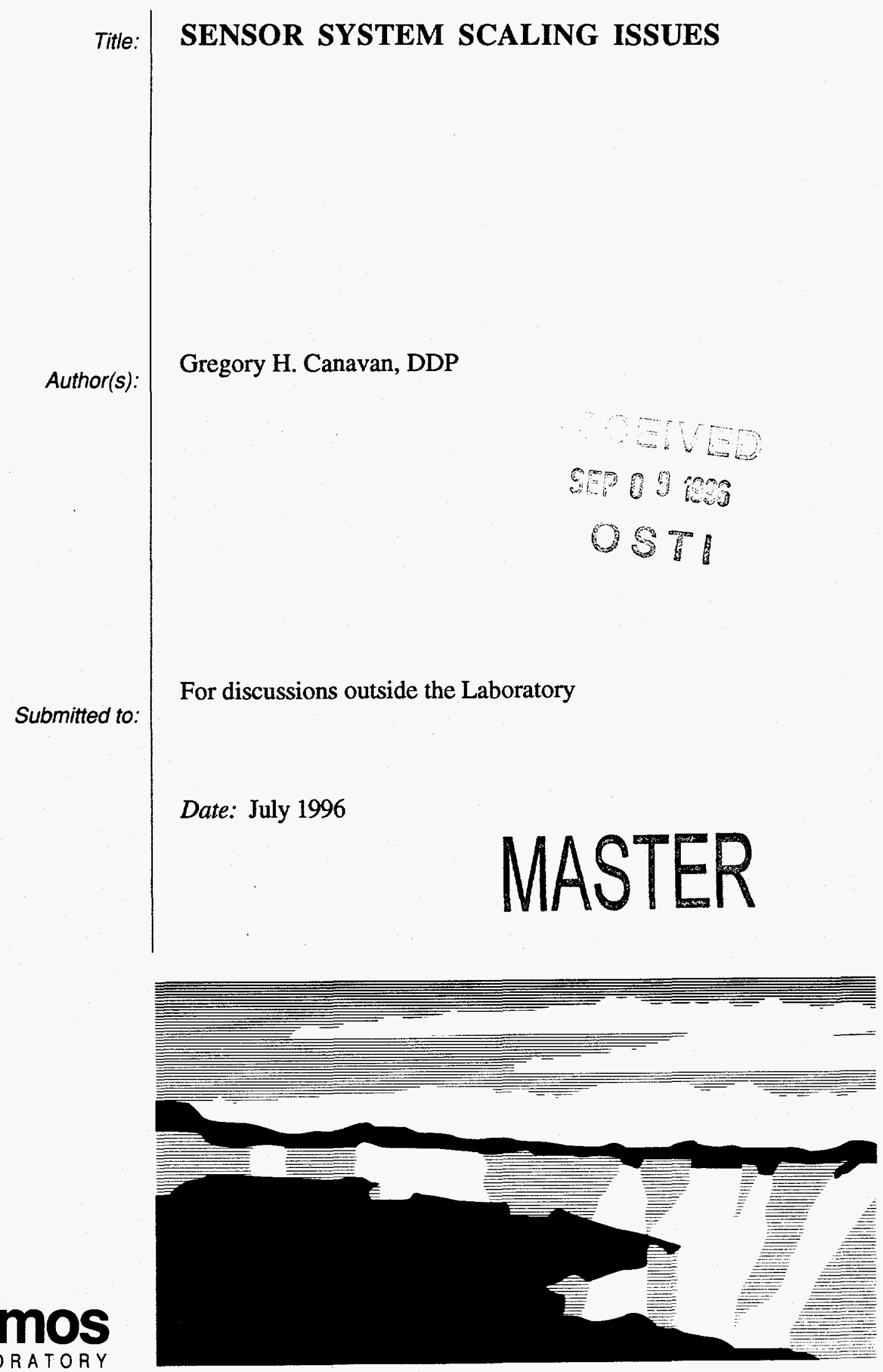




\section{DISCLAIMER}

Portions of this document may be illegible in electronic image products. Images are produced from the best available original document. 


\section{DISCLAIMER}

This report was prepared as an account of work sponsored by an agency of the United States Government. Neither the United States Government nor any agency thereof, nor any of their employees, makes any warranty, express or implied, or assumes any legal liability or responsibility for the accuracy, completeness, or usefulness of any information, apparatus, product, or process disclosed, or represents that its use would not infringe privately owned rights. Reference herein to any specific commercial product, process, or service by trade name, trademark, manufacturer, or otherwise does not necessarily constitute or imply its endorsement, recommendation, or favoring by the United States Government or any agency thereof. The views and opinions of authors expressed herein do not necessarily state or reflect those of the United States Government or any agency thereof. 


\title{
SENSOR SYSTEM SCALING ISSUES
}

\author{
Gregory H. Canavan
}

\begin{abstract}
A model for IR sensor performance is used to compare estimates of sensor cost effectiveness. Although, data from aircraft sensors indicate a weaker scaling, their agreement is adequate to support the assessment of the benefits of operating up to the maximum altitude of most current UAVs.
\end{abstract}

This note presents a model for infrared (IR) sensor performance, discusses its scaling, and uses it to compare estimates of sensor cost effectiveness. The model characterizes the sensors with parameters determined by detailed MRT calculations and measurements. Its analytic solutions predict ranges of 2 to $6 \mathrm{~km}$ for good visibility and 1 to 2 in poor. It can also predict the weights of sensors required to recognize targets, which increase rapidly with range. Data from aircraft sensors indicate a weaker scaling of mass on range. Thus, the model and aircraft data give quite different predictions of the ratio of swath width to sensor mass. However, their agreement at an altitude of about $8 \mathrm{~km}$ is adequate to support the assessment of operating up to the maximum altitude of most current UAVs.

Range prediction. The model for range prediction is defined by the equation $\mathrm{Te}^{-\mathrm{kr}}=\mathrm{Ae}^{\mathrm{mNr} / \mathrm{h}}$,

where $\mathrm{T}$ is the target's temperature difference from its surroundings, $\mathrm{k}$ is the atmospheric attenuation, $r$ is the range to target, $A$ is related to the sensor's sensitivity $\left(1 / D^{*}\right), N \approx 4$ is the number of line pairs across the target required for recognition, $h$ is the dimension of the target in meters, and $\mathrm{m}$ (cycles/mrad) is related to the MTF of the sensor optics. Table I gives the values of $A$ and $m$ inferred from MRTs provided by NVL for five capable FLIRs that would fit on UAVs. The sensor range is then

$$
\mathrm{r}=\ln (\mathrm{T} / \mathrm{A}) /(\mathrm{mN} / \mathrm{h}+\mathrm{k}) \text {, }
$$

from which the dependence of $\mathrm{r}$ on $\mathrm{T}$ and $\mathrm{A}$ is weak, but its dependence on $\mathrm{m}$ is strong, except when $\mathrm{k}$ is large, i.e., when visibility is very poor. The five NVL sensor's ranges vary from about 2 to $4 \mathrm{~km}$ for excellent visibility, where the Versatron gets up to about $6 \mathrm{~km}$, but they all drop to 1 to $2.5 \mathrm{~km}$ for the conditions characteristic of northern Europe.

Weight prediction as a function of range is performed by solving Eq. (1) for $\mathrm{m}=[\ln (\mathrm{T} / \mathrm{A}) / \mathrm{r}-\mathrm{k}] \mathrm{h} / \mathrm{N}$,

relating the MTF parameter $m$ to the optics diameter $D$ through $m=C \lambda / D$, where $C=2$ to 4 for current systems, and converting $D$ to mass $M$ through $M \approx K D^{3}$, where $K \approx 2,000 \mathrm{~kg} / \mathrm{m}^{3}$ for current systems. Figure 2 shows $D$ and $M$ for a sensor with the Versatron's $A$ and whatever $m$ is needed to meet the range required for good visibility conditions. The size naturally matches that 
of the actual Versatron at a range of about $7 \mathrm{~km}$; the mass is scaled to match it there. For shorter ranges the masses are so small that they would be dominated by fixed masses. For longer ranges they grow rapidly for $\mathrm{k}>0$, reaching about $400 \mathrm{~kg}$ by $20 \mathrm{~km}$.

Aircraft sensor data are also available in this size range. They are presented in Fig. 3 along with the NVL sensor masses and ranges. The aircraft sensors are not identified, but they are at the smallest and largest masses and at the longest ranges. The data turn up sharply for ranges greater than $10 \mathrm{~km}$, but it is not possible to tell from the few points there whether they turn up as fast as that from the above model in Fig. 2.

Figure of merit. A rough figure of merit for sensors is the swath they can cover. For a sensor that covers 45 degrees each side of nadir, its height is $r / \sqrt{2}$ and its swath is twice that or $\sqrt{2}$. It's cost is typically proportional to its mass, so its ratio of benefit to cost is proportional to $r \sqrt{2} / \mathrm{M}$, which is shown in Fig. 3 for the sensor with Versatron scaling of Fig. 2. The ratio falls rapidly with altitude, roughly as $1 / z^{2}$ for $z$ small, although the small sensor masses there would in practice be masked by fixed integration masses. The second curve shows the scaling inferred by $N R C$ from five airplane sensors, which is $M_{N}=1.7 r^{1.35}$, which gives $r \sqrt{ } 2 / M_{N} \approx 0.8 / r^{0.35}$, which varies much more slowly than the first. The curves cross at about $8 \mathrm{~km}$, but they disagree by a factor of 5 by $11 \mathrm{~km}$. The actual Versatron only reaches an altitude of about $5 \mathrm{~km}$, where the discrepancy is again about a factor of five.

Summary and conclusions. This note presents a model for IR sensor performance, discusses its scaling, and uses it to compare estimates of sensor cost effectiveness. The model characterizes the sensors with parameters determined but detailed MRT calculations and measurements. It admits of analytic solution, predicting ranges of 2 to $6 \mathrm{~km}$ for good visibility and 1 to 2 in poor. It can also be used to predict the weights of sensors required to recognize targets at given ranges, which increase rapidly with range. Data from aircraft sensors indicate a weaker scaling. The model and aircraft data give quite different predictions of the ratio of swath width to sensor mass. although their agreement at about $8 \mathrm{~km}$ is adequate to support the assessment of the benefits of operating up to the maximum altitude of most current UAVs. 


\section{SUMMARY UAV FLIR PAYLOAD INFORMATION}

\begin{tabular}{|c|c|c|c|c|c|}
\hline MODEL & $\begin{array}{l}\text { WFRAMETRICS } \\
\text { 445G MKII }\end{array}$ & $\begin{array}{l}\text { IAI TAMAM } \\
\text { POP-100 }\end{array}$ & VERSATRON & $\begin{array}{l}\text { RAFAEL } \\
\text { TOPAZ }\end{array}$ & $\begin{array}{c}\text { ULTRA } \\
\text { 3000D FSI }\end{array}$ \\
\hline FPA TECHNOLOGY & $\ln S b$ & PISi & InSb & HgCdTe & PtSi \\
\hline ARRAYFORMAT & $256 \times 256$ & $\begin{array}{c}320 \times 240 \mathrm{~Hz} \\
\text { Dither }\end{array}$ & $256 \times 256$ & $\begin{array}{c}240 \text { Scanning } \\
(\times 240)\end{array}$ & $320 \times 244$ \\
\hline SPECTRAL BAND, um & MWIR 3.4-5 & MWIR 3.5-5 & MWIR 3-5 & LWIR 8-12 & MWIR 3.5-5 \\
\hline WEIGHT (Ibs) & 39 & 33 & 45 & 52 & 36.7 \\
\hline POWER REQ. (Watts) & 200 & 130 & & 100 & 130 \\
\hline NFOV (deg) & 2.2 & $4 \times 3$ & $1.2 \times 0.9$ & $1.5 \times 1.9$ & $5 \times 4$ \\
\hline WFOV (deg) & 9.3 & $12.7 \times 9.5$ & $7 \times 5.2$ & $5.3 \times 6.7$ & $25 \times 19$ \\
\hline NIFOV (mrad) & 140 & 182 & 89 & $85 \times 110$ & \\
\hline NFOV eff (deg) & 2.2 & 3.464101615 & 1.039230485 & 1.688194302 & 4.472135955 \\
\hline WFOV eff & 9.3 & 10.98407939 & 6.033241252 & 5.959026766 & 21.79449472 \\
\hline NIFOV eff(deg) & 8.022 & 10.4286 & 5.0997 & 5.540646307 & \\
\hline WIFOV (mrad) & & & 560 & & \\
\hline STABILIZATION (urad) & 75 & 42 & 50 & 25 & \\
\hline OPTICAL SPEED & $F / 3$ & $F / 1.5$ & $F / 4$ & $F / 1.8$ & \\
\hline $\begin{array}{l}\text { WFOV DETECTION, } \\
\mathrm{km} \text { (Veh, } 0.75 \\
\text { c/mrad, } 4 \text { deg. dt, }\end{array}$ & 3.63 & 4.14 & 5.6 & 6.1 & 4.5 \\
\hline $\begin{array}{l}\text { NFOV RECOGNITION, } \\
\mathrm{km} \text { (Veh, } 3 \mathrm{cmrad}, 4 \\
\text { deg, dt, } 3.5 \mathrm{~m} \text { target) }\end{array}$ & 3.42 & 3.34 & 8.3 & 5.4 & 3.4 \\
\hline $\begin{array}{l}\text { NFOV DET/REC, } \mathrm{km} \\
\text { (Man, } 0.75 \mathrm{c} / \mathrm{mrad}, 4 \\
\text { deg dt, } 0.75 \mathrm{~m}\end{array}$ & 3.16 & 3.34 & 3.2 & 1.4 & . \\
\hline $\begin{array}{l}\text { SENSITIVITY (NETD, } \\
\text { deg) }\end{array}$ & & 2.92 & 0.025 & 0.1 & \\
\hline NOTES: & & & $\begin{array}{l}\text { F/4 } 130 \mathrm{~mm} \\
\text { Aper., } \\
500 \mathrm{~mm} / 80 \mathrm{~mm} \\
\text { lens }\end{array}$ & $\begin{array}{l}\text { Doesn't } \\
\text { indicate TDI } \\
\text { staring MWIR } \\
\text { options. } 3 \text { FOV } \\
\end{array}$ & $110 \mathrm{~mm}$ Lens \\
\hline \multicolumn{6}{|c|}{ EXPONENTIAL CURVE FIT PARAMETERS FOR MRTD } \\
\hline$A^{*}(300 K)$ & 0.0034 & 0.01 & 0.0022 & 0.035 & 0.012 \\
\hline$m *(300 K)$ & 1.44 & 1.54 & 0.88 & 0.85 & 2 \\
\hline $\begin{array}{l}{ }^{* *} 50 \% \text { PROB. REC } \\
\text { RNG,km - } 0.8 / \mathrm{km} \\
\text { Atm ext., dt=4, tgt }\end{array}$ & 2.49 & 2.05 & 3.19 & 2.04 & 1.75 \\
\hline
\end{tabular}

$$
\text { TABLE 4. }
$$




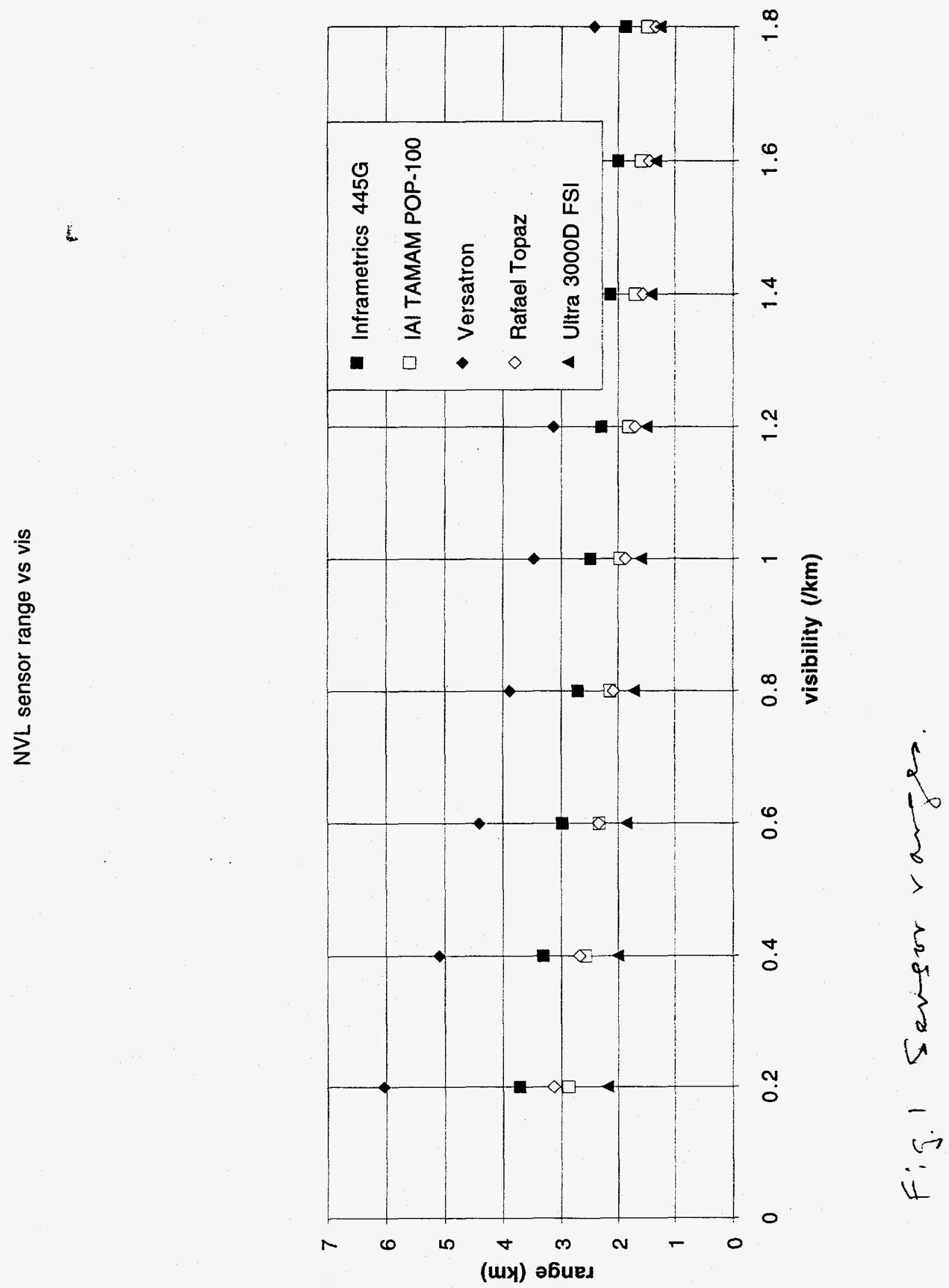




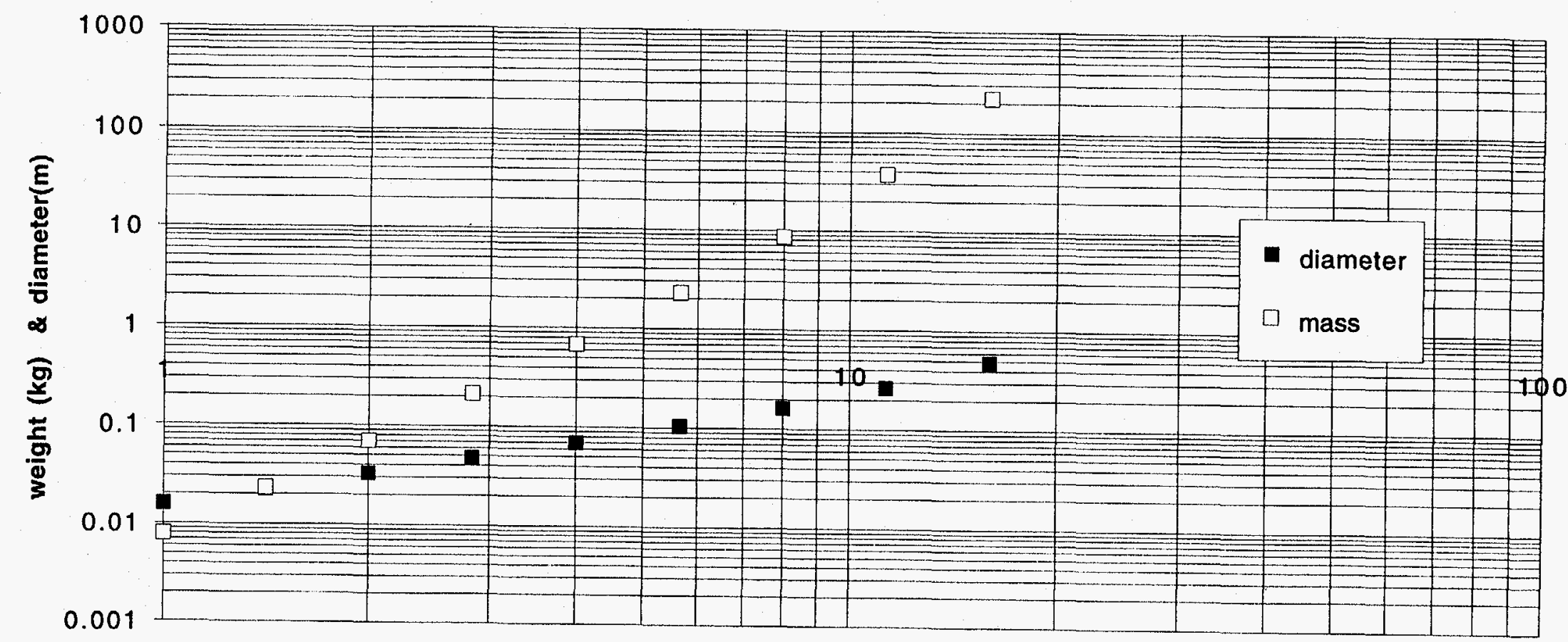

2. Sensor range and diameter versus weight.

sensor range (km) 
(uy) obued

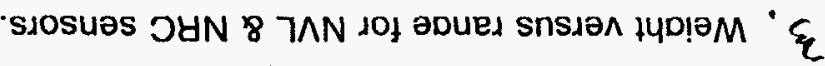

001

OL

1

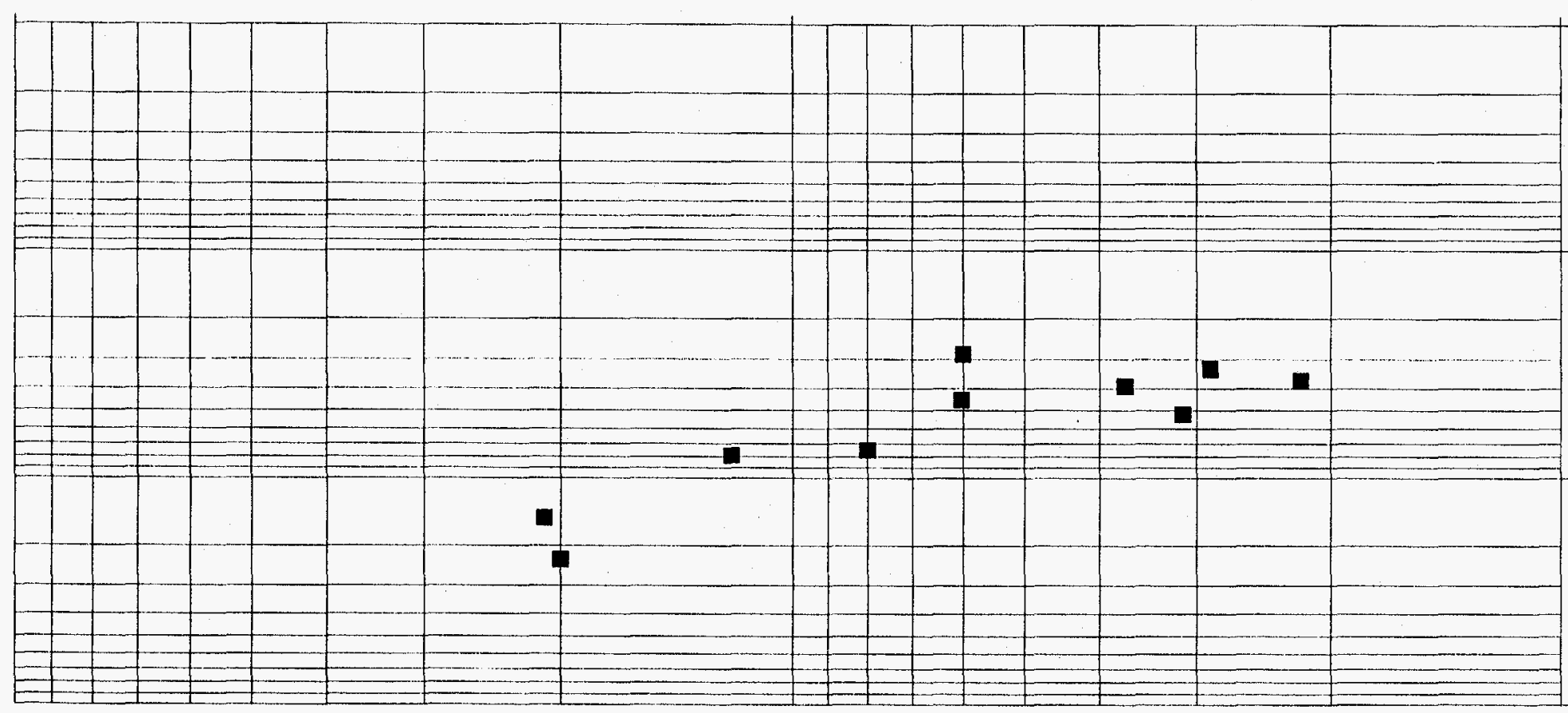

ol

$\frac{\frac{5}{0}}{\frac{1}{0}}$

001

0001 
Versatron vs NRC $W / m$ vs $z$



altitude (km)

4 Comparison of Versatron and NRC swath/mass estimates. 







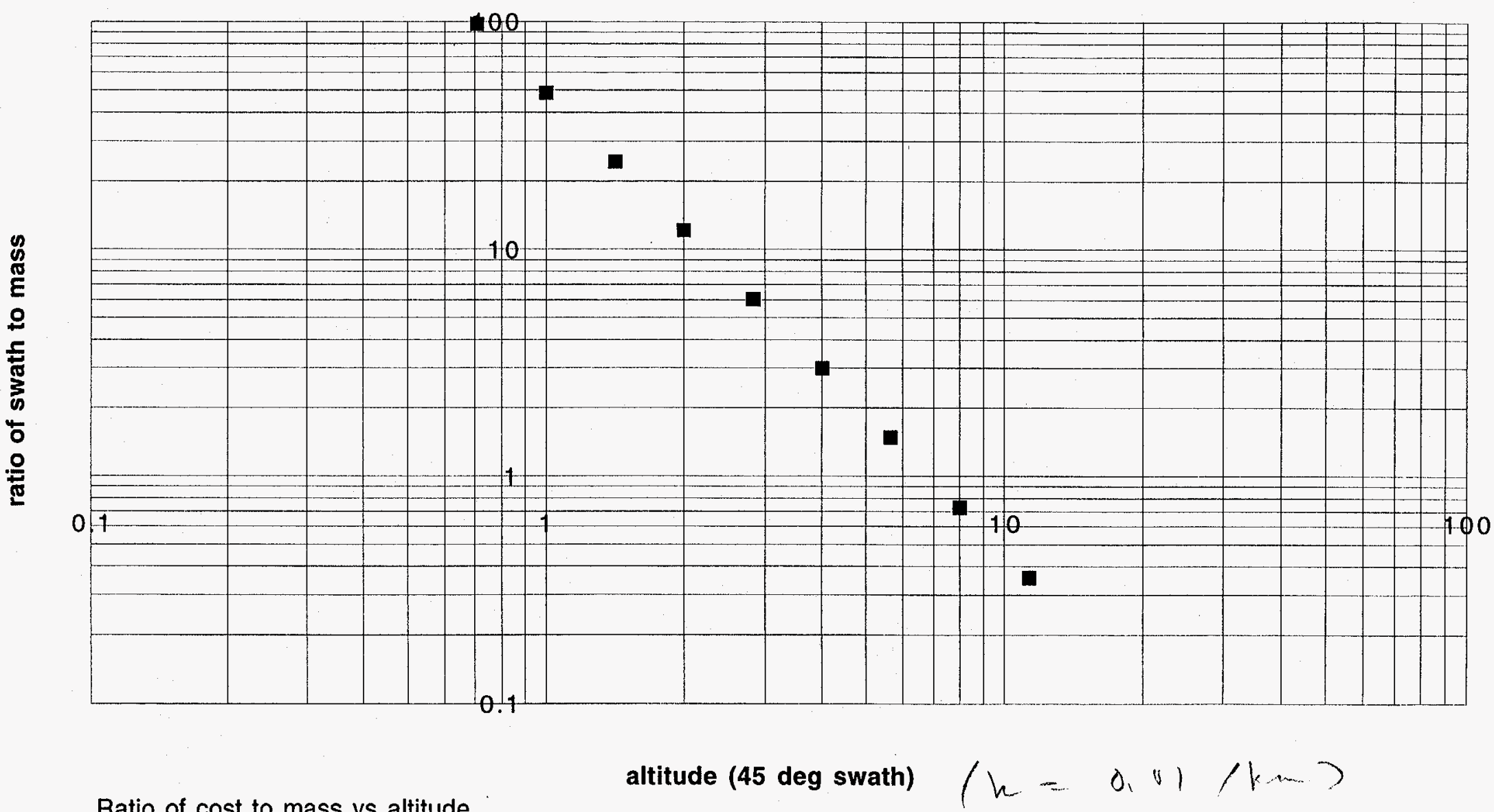

Ratio of cost to mass vs altitude. 